Research Articles

\title{
The Effect of two Different Culture Media on the Proliferation of Dental Pulp Stem Cells: Bovine Fetal Serum and Platelet Lysate
}

\author{
${ }^{1}$ Giuseppe Cicero, ${ }^{2}$ Veena Nanda and ${ }^{3}$ Irene Martini \\ ${ }^{1,2}$ Department of Periodontology and Implantology, College of Dentistry, New York University, New York, USA \\ ${ }^{3}$ BioEden, Italy
}

Article history

Received: 09-02-2015

Revised: 16-07-2015

Accepted: 12-09-2015

Correspondence Author:

Giuseppe Cicero

Department of Periodontology

and Implantology, College of

Dentistry, New York University,

New York, USA

E-mail: gc1675@nyu.edu

\begin{abstract}
Mesenchymal Stem Cells (MSCs) have been isolated from a variety of fetal and adult tissues and are considered an ideal source for cell-based therapy due to their unique properties such as multipotency and immunomodulatory functions. The aim of this work is to observe, analyze and investigate the morphology and proliferation of human dental pulp stem cells cultured in two different culture media: Fetal Bovine Serum (FBS) or platelet lysate. These cells would be cultured for a minimum period of 14 days to 3 months. The desired outcome is a pure culture of mesenchymal stem cells. With this present study we will determine which culture mediumpromotesthe most rapid formation of a pure culture of mesenchymal stem cells derived from Dental Pulp Stem Cells (DPSC).
\end{abstract}

Keywords: Stem Cells, Dental Pulp, Culture Media

\section{Introduction}

Stem cells are undifferentiated cells that are able to undergo an indefinite number of cell cycles, are capable of self-renewal and can produce highly specialized cells (Ramalho-Santos and Willenbring, 2007). Recently stem cells have raised a lot of interest in the medical field. Many researchers and clinicians are now studying the possible uses of these cells as precursors of osteoblasts for bone regeneration and the application of these cells in tissue-engineering (Seong et al., 2010; Khanna-Jain et al., 2012). Dentistry has started to explore the potential applications of stem cells to regenerate and repair compromised dental structures (Amabile and Meissner, 2009). A new and recent source of mesenchymal stem cells has been found in deciduous teeth; in particular, the dental pulp of deciduous teeth, which is the object of this study (Miura et al., 2003).

\section{Objectives}

The objective of this study is to compare the results of two trials. Both methods shared the same protocol, the only difference being the use of two different culture media. We want to analyze how dental pulp stem cells behave when grown with fetal bovine serum compared to platelet lysate.

\section{Materials and Methods}

The subjects of this experiment are dental pulp stem cells extracted from 9 deciduous second mandibular molars extracted from patients aged 9-10 years.

Each tooth is collected and placed in a $50 \mathrm{~mL}$ Falcon tube containing pasteurized cow milk at a temperature of $4^{\circ} \mathrm{C}$, in order to sustain and support mammalian cells health and functionality. Milk is highly regulated for content sterility and production specification. It also has antibacterial, antifungal, antiviral and antiparasite properties (Olson et al., 1997; Fagade, 2004).

After verifying the integrity of the pulp chamber and roots, the dental pulp was extracted. The pulp was then transferred into a $50 \mathrm{~mL}$ falcon tube filled with PBS (phosphate buffered saline) (Suchánek et al., 2007).

All living cellular material is isolated from the tooth upon arrival using a mechanical method. Secondarily a chemical selection process occurs which promotes the health and viability of MSC's and retards the growth and health of all other cell types. This process can take as long as 21 days depending on the individual sample. The final step is testing to make sure the final material passes all requirements for cellular identity and subsequent cryopreservation. 


\section{Protocol $A$}

After a first phase of centrifugation, enzymatic digestion, burker count and cytofluorimetric characterization the cells were then put in culture for the amplification process (Suchánek et al., 2007).

The cells that have been obtained are then put in flasks (T75 cm2 BD Falcon and T25 cm2 BD Falcon) and cultured in Dulbecco's Modified Eagle Medium (DMEM) low glucose with sodium pyruvate culture (Biowest) added with 5\% platelet lysate, 1\% Lglutamine (Gibco) and 1\% penicillin and streptomycin (Gibco) (Anitua, 2001; Lucarelli et al., 2003).

Before adding the platelet lysate to the culture, heparin was added at the concentration of $2 \mathrm{U} / \mathrm{ML}$. The culture was then finally filtered with 0.22 micron filters.

The flasks are then incubated at the temperature of $37^{\circ} \mathrm{C}$ with $5 \% \mathrm{CO}_{2}$. The first culture change is done after 24-48h and the rest of the culture changes every $72 \mathrm{~h}$ (Suchanek et al., 2009).

Five platelet donors were randomly selected to prepare the platelet lysate. The extracted platelets were then centrifuged in order to have a concentration of $1.5 \times 10^{5}$. After the centrifugation process, separate portions were prepared. Each portion underwent three freezing processes at $-80^{\circ} \mathrm{C}$ and three de-freezing processes at $37^{\circ} \mathrm{C}$. Ultimately a centrifugation at $300 \mathrm{rmp}$ for $20 \mathrm{~min}$ was performed and the supernatant was collected in order to collect PRP (platelet rich plasma) (Landesberg et al., 2000; Marx et al., 1998).

The next steps have been done to verify the identity, proliferation and vitality of DPSC cells cultured with platelet lysate.

The DPSC put in culture are analyzed with surface antigens through a cytomety test (FACS Calibure flow cytometer BD bioscience). Monoclonal antibodies against CD90, CD105, CD31 and CD45 were utilized. The antibodies are added to the population of 100,000 cells and then incubated for $30 \mathrm{~min}$ at a temperature of $4^{\circ} \mathrm{C}$ in the dark. After incubation, the cells are washed and analyzed with acytometry test (Martens et al., 2012).

The vitality and proliferation of DPSC is analyzed after 14 days in culture. The cells that have been put in culture are incubated in a Dulbecco's Phosphate Buffered Saline (DPBS) solution containing $0.5 \mathrm{mM}$ of calcein Am (green fluorescence) and $0.5 \mathrm{~mm}$ ethidiumhomodimer (red fluorescence) for $45 \mathrm{~min}$ at the temperature of $28^{\circ} \mathrm{C}$. The solution of DPBS that was utilized is then replaced with new DPBS. The vital cells are colored in green while the necrotic cells are colored in red by the fluorescence microscopy test (Abdullah et al., 2014).

\section{Protocol a Results}

The results of this first phase of the study have shown the presence of ahematopoietic CD45+ component, both in the pre-manipulation and postmanipulation process with a media percentage of $1.13+/-0.61$ in the pre-manipulation phase and of $13.5+/-5.72$ in the post-manipulation phase. In the culture media that was enriched with platelet lysate at $5 \%$ there was evidence of megacarioblast aggregates and the cytoflurmetric characterization showed that in four of the experiments post-amplification a media percentage of CD61 (b3 integrin) equal to 2.02+/1.47. An increase in the expression of any mesenchymal marker was not seen (Table 1).

In the experiments 4 to 9 there are significant changes in the presence of some cell populations with respect to others. In particular there is a higher percentage of cells with CD45+ characteristics and a lower percentage of CD90, CD 105positive cells (Table 2). These results suggest that experimental population of cells obtained in vitro isa mixed population and does not represent the characteristics of a pure mesenchymal stem cell population that was expected to be seen (Karamzadeh et al., 2012).

\section{Protocol $B$}

The same study has been performed but with some variations in the protocol regarding the use of a different culture media. Fetal Bovine Serum (FBS) was used instead of platelet lysate.

The FBS method followed the same protocol used for the first experiment except the cells are this time transferred in T75 Falcon tubes with Phosphate Buffered Saline (PBS) and after 3 hours put in culture at $37^{\circ} \mathrm{C}$ with $5 \% \mathrm{CO}_{2}$ with growth factors containing $15 \% \mathrm{FBS}$, $100 \mathrm{~mm} \mathrm{~L}$ ascorbic acid, $2 \mathrm{~mm}$ of $\mathrm{L}$ glutamine and $100 \mathrm{U} / \mathrm{ml}$ of penicillin and $100 \mathrm{mg} / \mathrm{mL}$ of streptomycin in the modified alpha form of eagle.

\section{Results Using Protocol B}

This protocol involved the use of FBS instead of the platelet lysate. The following chart represents acytofluorimetricanalysis (Fig. 1). The preliminary results of the experiments demonstrate that the use of FBS $15 \%$ instead of the platelet lysate gave a positive outcome for a selection of mesenchymal cells. After a first phase of amplification the cell population had typical characteristic of mesenchymal cells, which is expressed by a high positivity to markers such as CD90 E CD45. These markers are positive in more than $80 \%$ of the cell population that have been tested. 
Table 1. Quantification of stem cell surface markers by flow cytometry (expressed in mean percentage) in dental pulp stem cells when grown in a platelet-rich plasma

\begin{tabular}{|c|c|c|c|c|c|c|c|c|c|c|}
\hline & $\begin{array}{l}\text { Total number } \\
\text { of cells }\end{array}$ & CD90 & CD45 & $\begin{array}{l}\text { CD105 (gate } \\
\text { CD90+/ CD45-) }\end{array}$ & $\begin{array}{l}\text { CD31 (gate } \\
\text { CD90+/ CD45-) }\end{array}$ & CD61 & CD41 & $\begin{array}{l}\text { CD61/ } \\
\text { CD41 }\end{array}$ & $\begin{array}{l}\text { 7AAD } \\
\%\end{array}$ & $\begin{array}{l}\text { CD90+ } \\
\text { /CD45- }\end{array}$ \\
\hline$\overline{\text { EXP } 1}$ & $24,6 \times 10^{6}$ & 7,8 & 0,5 & 2,3 & 1,4 & & & & 99,4 & \\
\hline EXP 2 & $11,9 \times 10^{6}$ & 6,2 & 0,2 & 0,5 & 0,5 & & & & 98,9 & \\
\hline EXP 3 & $18 \times 10^{6}$ & 4,3 & 1,1 & 0,2 & 0 & & & & 98,6 & \\
\hline $\begin{array}{l}\text { EXP } 3 \\
\text { PO }\end{array}$ & $10 \times 10^{6}$ & 2,9 & 0,1 & 0,1 & 0,1 & & & & 98 & \\
\hline EXP 4 & $9,1 \times 10^{6}$ & 9,6 & 1,7 & 1,2 & 1,4 & & & & 98 & 7,4 \\
\hline $\begin{array}{l}\text { EXP } 4 \\
\text { PO }\end{array}$ & $4 \times 10^{5}$ & 5,1 & 20,9 & 2,2 & 3,1 & & & & 98 & 2,2 \\
\hline EXP 5 & $7,35 \times 10^{6}$ & 9,3 & 1,7 & 1,4 & 1,6 & & & & 98 & 7,5 \\
\hline $\begin{array}{l}\text { EXP } 5 \\
\text { PO }\end{array}$ & $6,7 \times 10^{6}$ & 4,6 & 12,4 & 0,2 & 0,3 & & & & 99,5 & 4,2 \\
\hline EXP 6 & $4,55 \times 10^{6}$ & 5,3 & 1,4 & 0 & 0,2 & & & & 98 & 3,2 \\
\hline $\begin{array}{l}\text { EXP } 6 \\
\text { PO }\end{array}$ & $3,55 \times 10^{6}$ & 7,2 & 7,7 & 0,3 & 0,8 & 1,3 & & & 83,8 & 0,8 \\
\hline EXP 7 & $4,55 \times 10^{6}$ & 7,3 & 1,4 & 0 & 0,4 & & & & 98,8 & 4,9 \\
\hline $\begin{array}{l}\text { EXP } 7 \\
\text { PO }\end{array}$ & $2,3 \times 10^{6}$ & 5,4 & 19 & 0,2 & 1 & 1,6 & & & 84,2 & 0,5 \\
\hline EXP 8 & $5,49 \times 10^{6}$ & 8,5 & 1,8 & 0 & 0,4 & & & & 96,1 & 6 \\
\hline EXP 8 & $1,6 \times 10^{5}$ & 3 & 11,9 & 1,9 & 1 & 1 & & & 98,6 & 0,9 \\
\hline EXP 9 & $11,7 \times 10^{6}$ & 9,2 & 0,4 & 0,4 & 0,2 & & & & 97,5 & 7,4 \\
\hline $\begin{array}{l}\text { EXP } 9 \\
\text { PO }\end{array}$ & $3 \times 10^{5}$ & 7,9 & 7 & 5,2 & 12,6 & 4,2 & 4,2 & 3,9 & 96,1 & 2 \\
\hline
\end{tabular}

Table 2. Quantification of stem cell surface markers both before and after amplification expressed in mean percentage

\begin{tabular}{lllllll}
\hline & & Cells/totx $10^{0}$ & DC90pos/CD45neg & CD105 & CD31 & Viability (7AAD neg) \\
\hline Pre & Media & 7,12 & 6,07 & 0,5 & 0,7 & 97,73 \\
Pre & Dev stand & 2,86 & 1,74 & 0,64 & 0,63 & 0,9 \\
Post & Media & 3,52 & 1,77 & 1,67 & 3,31 & 93,37 \\
Post & Dev stand & 1,78 & 1,38 & 1,95 & 4,74 & 7,34 \\
\hline
\end{tabular}
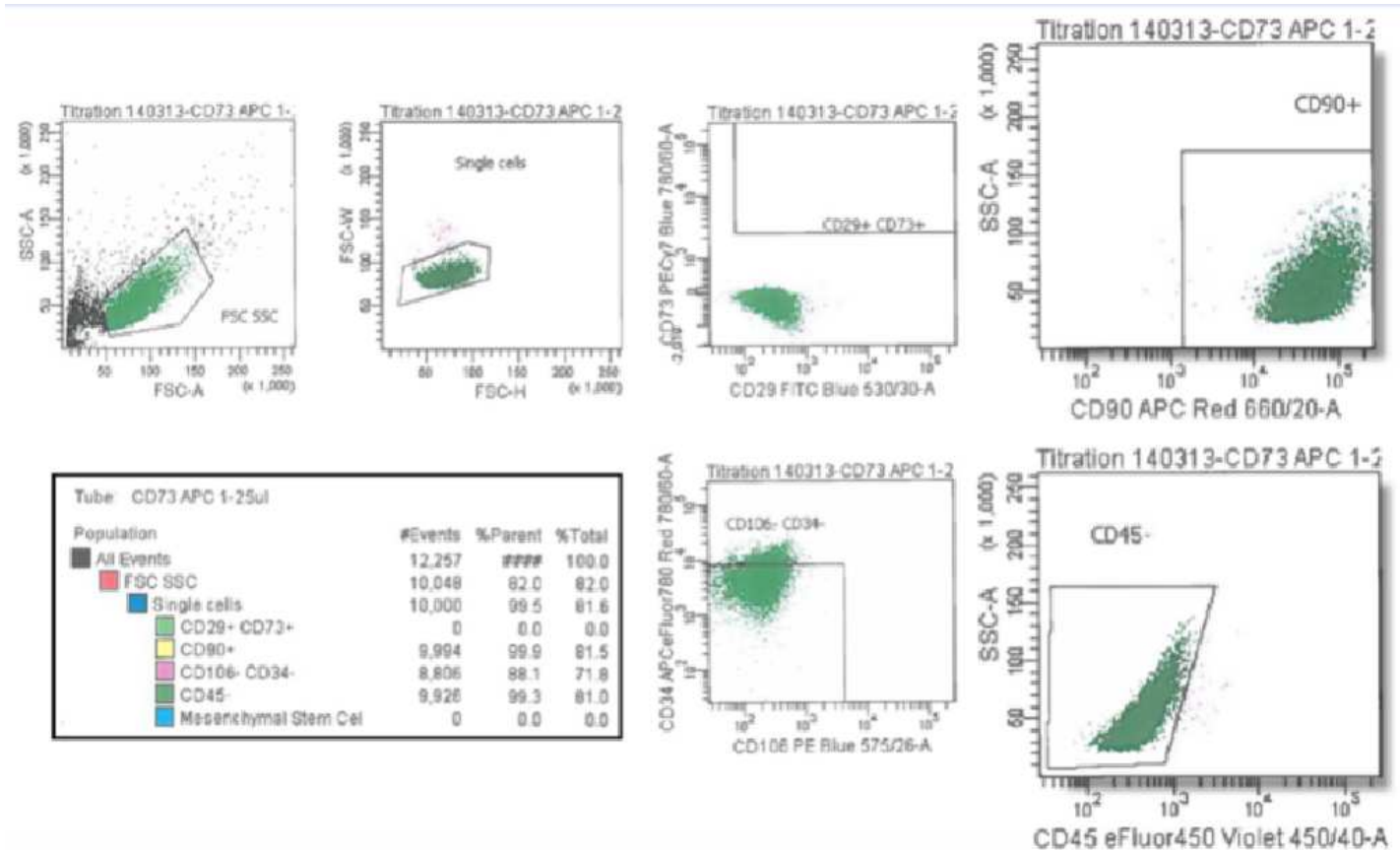

Fig. 1. Cytofluorimetric analysis of human dental pulp stem cells when grown in a fetal bovine serum rich culture media 


\section{Discussion}

This study comparing the results of two laboratory culture methods represents the first phase of a long scientific analysis that considers the dental pulp stem cells for future utilization in clinical therapy.

Even though different articles state that the use of platelet lysate promotes and increases the proliferation of dental pulp mesenchymal stems cells (Schallmoser et al., 2007; Bieback et al., 2009) and can efficiently substitute for the use of fetal bovine serum in clinical trials, our experiment verified that fetal bovine serum as a culture medium produces a more pure culture of mesenchymal cells than a culture medium of platelet lysate (Azouna et al., 2012; Doucet et al., 2005; Lee et al., 2011).

The results of these experiments put into perspective how the use of platelet lysate influenced the growth of hematopoietic cell line instead of a stromal cell line. In fact, after the initial phase of amplification the first experimental population of cells showed fewer cells with stromal characteristics and more cells with megacarioblast characteristics. This data may be helpful in understanding the factors that influence the dynamics of cell growth and proliferation induced by different culture media such as platelet lysate and FBS.

The data suggests that platelet lysate is not a preferred culture medium for dental pulp stem cell proliferation. When FBS was used instead almost the entire population of cells had acquired characteristics of "stemness" confirmed by the high positivity to the marker CD90 and negativity to the CD45 marker, typical of the stromal lineage.

In relation to the initial objectives of this study we can state the following: The amplification of a population of pure mesenchymal stem cells has been observed only when fetal bovine serum was used as a culture media. When platelet lysate was used we observed a mixed cell culture with a prevalence of megacaryoblast-like cells and a lack of expected mesenchymal stem cells that could be considered for future clinical purposes.

\section{Conclusion}

The identification of mesenchymal cells with ectodermic characteristics is a topic of serious interest for future clinical therapies. This cell population, presenting a primordial nature, could be utilized for retro- inductive protocols to an embryonic condition that would guarantee a vast spectrum of therapeutic uses.

Through the analysis of the experiments we can confirm that the results of our study, that FBS is a better culture medium than platelet lysate for the production of a pure mesenchymal stem cell population, should be considered, even though preliminary, when establishing future clinical and therapeutic research protocols.

\section{Author's Contributions}

Giuseppe Cicero: Designed the research plan and organized the study. Participated in all experiments, coordinated the data analysis and contributed to the writing of the manuscript.

Veena Nanda: Contributed to the writing of the manuscript.

Irene Martini: Designed the research plan and organized the study. Participated in all experiments, coordinated the data analysis and contributed to the writing of the manuscript.

\section{Ethics}

This article is original and contains unpublished material. The corresponding author confirms that all of the other authors have read and approved the manuscript and no ethical issues involved.

\section{References}

Abdullah, M.F., S.F. Abdullah, N.S. Omar, Z. Mahmood and S.N. FazliahMohdNoor et al., 2014. Proliferation rate of stem cells derived from human dental pulp and identification of differentially expressed genes. Cell BiolInt., 38: 582-590.

DOI: $10.1002 /$ cbin. 10229

Amabile, G. and A. Meissner, 2009. Induced pluripotent stem cells: Current progress and potential for regenerative medicine. Trends Mol. Med., 15: 59-68. DOI: 10.1016/j.molmed.2008.12.003

Anitua, E., 2001. The use of Plasma-Rich Growth Factors (PRGF) in oral surgery. Pract. Proced. Aesthet. Dent. 13: 487-493. PMID: 11544821

Azouna, N.B., F. Jenhani, Z. Regaya, L. Berraeis and T.B. Othman et al., 2012. Phenotypical and functional characteristics of mesenchymal stem cells from bone marrow: Comparison of culture using different media supplemented with human platelet lysate or fetal bovine serum. Stem Cell Res., Ther. 3: 6-6. DOI: $10.1186 /$ scrt97

Bieback, K., A. Hecker, A. Kocaomer, H. Lannert and K. Schallmoser et al., 2009. Human alternatives to fetal bovine serum for the expansion of mesenchymal stromal cells from bone marrow. Stem Cells, 27: 2331-2341. DOI: 10.1002/stem.139

Doucet, C., I. Ernou, Y. Zhang, J.R. Llense and L. Begot et al., 2005. Platelet lysates promote mesenchymal stem cell expansion: A safety substitute for animal serum in cell-based therapy applications. J. Cell Physiol., 205: 228-236. PMID: 15887229 
Fagade, O., 2004. Extra-alveolar storage media for tooth autotransplants and replants. Internet J. Dental Sci.

Karamzadeh, R., M.B. Eslaminejad and R. Aflatoonian, 2012. Isolation, characterization and comparative differentiation of human dental pulp stem cells derived from permanent teeth by using two different methods. J. Vis Exp. DOI: 10.3791/4372

Khanna-Jain, R., B. Mannerström, A. Vuorinen, G.K. Sándor and R. Suuronen et al., 2012. Osteogenic differentiation of human dental pulp stem cells on $\beta$ tricalcium phosphate/poly (1-lactic acid/caprolactone) three-dimensional scaffolds. J. Tissue Eng. DOI: 10.1177/2041731412467998

Landesberg, R., M. Roy and R.S. Glickman, 2000. Quantification of growth factor levels using a simplified method of platelet-rich plasma gel preparation. J. Oral Maxillofac. Surg., 58: 297-300. DOI: 10.1016/S0278-2391(00)90058-2

Lee, J.Y., H. Nam, Y.J. Park, S.J. Lee and C.P. Chung et al., 2011. The effects of platelet-rich plasma derived from human umbilical cord blood on the osteogenic differentiation of human dental stem cells. In vitro Cell. Dev. Biol. Anim., 47: 157-164. DOI: $10.1007 /$ s1 1626-010-9364-5

Lucarelli, E., A. Beccheroni, D. Donati, L. Sangiorgi and A. Cenacchi et al., 2003. Platelet-derived growth factors enhance proliferation of human stromal stem cells. Biomaterials, 24: 3095-3100. DOI: 10.1016/S0142-9612(03)00114-5

Martens, W., E. Wolfs, T. Struys, C. Politis and A. Bronckaers et al., 2012. Expression pattern of basal markers in human dental pulp stem cells and tissue. Cells Tissues Organs, 196: 490-500. DOI: 10.1159/000338654

Marx, R.E., E.R. Carlson, R.M. Eichstaedt, S.R. Schimmele and J.E. Strauss et al., 1998. Plateletrich plasma: growth factor enhancement for bone grafts. Oral Surg. Oral Med. Oral Pathol. Oral Radiol. Endod., 85: 638-646. PMID: 9638695
Miura, M., S. Gronthos, M. Zhao, B. Lu and L.W. Fisher, 2003. SHED: Stem cells from human exfoliated deciduous teeth. Proc. Natl. Acad. Sci. U.S.A., 13: 5807-5812. PMID: 12716973

Olson, B.D., J.M. Mailhot, R.W. Anderson, G.S. Schuster and R.N. Weller, 1997. Comparison of various transport media on human periodontal ligament cell viability. J. Endod., 23: 676-679. PMID: 9587306

Ramalho-Santos, M. and H. Willenbring, 2007. On the origin of the term "stem cell". Cell Stem. Cell, 1: 35-38. DOI: 10.1016/j.stem.2007.05.013

Schallmoser, K., C. Bartmann, E. Rohde, A. Reinisch and K. Kashofer et al., 2007. Human platelet lysate can replace fetal bovine serum for clinical-scale expansion of functional mesenchymal stromal cells. Transfusion, 47: 1436-1446. PMID: 17655588

Seong, J.M., B.C. Kim, J.H. Park, I.K. Kwon and A. Mantalaris et al., 2010. Stem cells in bone tissue engineering. Biomed Mater. DOI: $10.1088 / 1748-6041 / 5 / 6 / 062001$

Suchanek, J., T. Soukup, B. Visek, R. Ivancakova and L. Kucerova et al., 2009. Dental pulp stem cells and their characterization. Biomed Pap Med. Fac. Univ. Palacky Olomouc Czech Repub, 153: 31-35. PMID: 19365523

Suchánek, J., T. Soukup, R. Ivancaková, J. Karbanová and V. Hubková et al., 2007. Human dental pulp stem cells isolation and long term cultivation. Acta Medica (Hradec Kralove), 50: 195-201. PMID: 18254273 